\title{
Shading stress after heading enhances the remobilization of nonstructural carbohydrates in rice under different ecological conditions
}

\author{
Yuling Zeng ${ }^{1,2}$, Qiuping $\mathrm{Li}^{1,2}$, Hong Chen ${ }^{1,2}$, Bo Lii, ${ }^{1,2}$, Xiaoyuan Zhong ${ }^{1,2}$, Zhenzhen $\mathrm{Li}^{1,2}$, Hui Lu ${ }^{1,2}$, \\ Li Wang ${ }^{1}$, Wanjun Ren ${ }^{1,2}$, and Fei Deng ${ }^{1,2^{*}}$
}

${ }^{1}$ Sichuan Agricultural University, College of Agronomy, Key Laboratory of Crop Ecophysiology and Farming System in Southwest China of Ministry of Agriculture, Chengdu 611130, China.

${ }^{2}$ Crop Ecophysiology and Cultivation, Key Laboratory of Sichuan Province, Chengdu 611130, China.

"Corresponding author (ddf273634096@163.com).

Received: 11 December 2020; Accepted: 15 March 2021; doi:10.4067/S0718-58392021000300300

\begin{abstract}
Low light levels during rice (Oryza sativa L.) growing seasons may lead to significant reductions in grain yield and quality. The effect of shading stress on remobilization of nonstructural carbohydrates (NSC) from the stem plus sheath (SPS) to the grain, a process crucial to rice grain formation, was investigated. Field shading experiments were conducted in Hanyuan and Wenjiang, China, using two rice varieties (Huanghuazhan and Guichao II) subjected to shading stress after heading. Stored NSC of 60.00-159.15 $\mathrm{g} \mathrm{m}^{-2}$ were remobilized from SPS after heading, contributing $9.63 \%-23.63 \%$ to grain dry weight at maturity. Shading stress resulted in the $23.99 \%-50.30 \%$ and $31.65 \%-61.33 \%$ reduction in NSC content of SPS at $20 \mathrm{~d}$ after heading (DAH20) and maturity stages, respectively. This contributed to the $13.80 \%-89.00 \%$ increase in the remobilization of stored NSC from SPS to the grain (RASN) and $15.86 \%-73.30 \%$ increase in remobilization percentage of removed NSC from SPS to the grain (RPRN). The effect of shading stress on remobilization differed between sites and varieties. Owing to a greater sink capacity, shading stress led to a higher RASN and RPRN from heading to DAH20 for 'Huanghuazhan' in Hanyuan. To compensate for photosynthate deficiency under shading stress, rice is adapted to remobilize stored NSC during early grain filling stages. Consequently, grain yield loss caused by shading could be reduced by increasing the SPS remobilization ability (especially in low light areas). Increasing NSC accumulation in SPS before heading for later remobilization may be a feasible way to alleviate rice yield loss under adverse light conditions.
\end{abstract}

Key words: Nonstructural carbohydrates, Oryza sativa, remobilization characteristics, shading stress, yield.

\section{INTRODUCTION}

By the middle of this century, an estimated $40 \%$ of the world's population will face a food resource shortage (IbarrolaRivas et al., 2017). Rice (Oryza sativa L.), one of the three major food crops, is cultivated in more than 100 countries, with Asian countries accounting for $90 \%$ of the total crop yield (Fukagawa and Ziska, 2019). In China, rice is a staple for more than $60 \%$ of the population, and accounts for $40 \%$ of the total rice production globally (Wu et al., 2013); however, the cultivated area under rice has declined due to rapid development of cities and ongoing population growth. Consequently, there is an urgent need to improve rice production to meet future demands under these severe resource challenges (BaileySerres et al., 2019).

In recent years, increased environmental pollution and frequency of extreme climate events have seriously affected food production (Shao et al., 2019). In China and other countries, increased rainfall and decreased hours of sunshine 
during the rice growth period are widespread (Chou et al., 2019; Ray et al., 2019), and heavy haze and aerosol pollution may further decrease solar irradiance by $28 \%-49 \%$ (Tie et al., 2016). The harsh light environment may seriously hinder the growth and development of this light-loving crop, resulting in decreased grain yield and quality (Liu et al., 2019). For example, if shading occurs before the heading stage, the number of effective panicles and spikelet differentiation may decrease (Deng et al., 2009; Wei et al., 2018), with a consequent decrease in grain filling capacity. If shading occurs after the heading stage, it may significantly decrease the spikelet filling rate and grain weight, with a consequent decrease in crop yield (Wang et al., 2015).

As rice crop yield is closely related to carbohydrates produced during photosynthesis, light energy utilization is key to rice production (Priyanka et al., 2019). Although rice plants show an increase in light capturing capacity under shading stress through an increase in chlorophyll content, there is a decrease in net photosynthetic rate, saturation irradiance, electron transport rate, along with a limited supply of electrons for photoreactive metabolism (Wang et al., 2015). Therefore, under shading stress, the production of rice photosynthates is limited, which consequently limits plant growth and development (Liu et al., 2019).

Rice yield depends not only on photosynthesis after the heading stage but also on the remobilization of carbohydrates stored before heading in the vegetative organs, particularly in the stem plus sheath (SPS) (Fu et al., 2011; Stella et al., 2016). These remobilized carbohydrates, also known as nonstructural carbohydrates (NSC), are soluble sugars and starch (Panda and Sarkar, 2014) which play an extremely important role in rice yield formation by contributing to C reserves and grain filling (Deng et al., 2016). For example, the SPS NSC concentration in rice can reach up to $4 \mathrm{t} \mathrm{ha}^{-1}$ (Fu et al., 2011). Normally, the rapid remobilization of NSC from the SPS to the grain (RASN) after heading contributes about $30 \%$ to the final grain weight (Pan et al., 2011; Panda and Sarkar, 2014). Although the filling rate of seeds is related to the NSC content of SPS before heading (Liang et al., 2017), the efficacy of RASN is also an important indicator of rice production potential (Slewinski, 2012).

Grain weight can be estimated by measuring the redistribution of NSC; however, the SPS NSC content is affected by environmental factors. For example, RASN increases under water stress, leading to increased grain filling and yield (Yang et al., 2001; Yang and Zhang, 2006). In contrast, under high temperature stress, the NSC remobilization from the SPS is inhibited (Zhen et al., 2019). There is evidence that shading conditions may reduce SPS DM accumulation and increase the output and conversion rate of stored photosynthetic products (Ren et al., 2003; Liu et al., 2019). However, how shading stress affects NSC accumulation and remobilization from the SPS under different ecological conditions has rarely been reported.

In our study, a shading stress field experiment using two rice varieties was carried out in Wenjiang and Hanyuan from 2018 to 2019. The main objectives of the present study were: (1) to investigate the accumulation of NSC before heading and the remobilization of NSC from the SPS under shading stress after heading; (2) to explore the contribution of SPS NSC to grain yield under shading stress after heading; and (3) to compare the difference of NSC remobilization under different ecological conditions. The present study provides a theoretical basis for agronomists to improve rice yield under abiotic stress.

\section{MATERIALS AND METHODS}

The field experiments were conducted in Hanyuan $\left(29^{\circ} 29^{\prime} \mathrm{N}, 102^{\circ} 37^{\prime} \mathrm{E}\right)$ and Wenjiang ( $\left.30^{\circ} 43^{\prime} \mathrm{N}, 103^{\circ} 52^{\prime} \mathrm{E}\right)$, Sichuan Province, PR China, in 2018 and 2019. Both sites are located in a subtropical monsoon humid climate. The climate data during the experimental period and the soil characteristics of the study sites were the same as reported by Li et al. (2020). The mean maximum and minimum temperatures and precipitation in Hanyuan were all lower than Wenjiang except for the maximum and minimum temperatures during shading period in 2018 and the maximum temperature after heading in 2019. The total radiation of Hanyuan in $2 \mathrm{yr}$ was higher than Wenjiang; it was $2240.3 \mathrm{MJ} \mathrm{m}^{-2}\left(654.3 \mathrm{MJ} \mathrm{m}^{-2}\right.$ during shading period) and 2285.6 $\mathrm{MJ} \mathrm{m}^{-2}$ (564.4 $\mathrm{MJ} \mathrm{m}^{-2}$ during shading period) in 2018 and 2019, respectively. In Wenjiang, it was recorded $1783.3 \mathrm{MJ} \mathrm{m}^{-2}$ (548.6 $\mathrm{MJ} \mathrm{m}^{-2}$ during shading period) and $1678.3 \mathrm{MJ} \mathrm{m}^{-2}\left(502.9 \mathrm{MJ} \mathrm{m}^{-2}\right.$ during shading period) in 2018 and 2019, respectively. The soil of the field in Hanyuan contained $25.50 \mathrm{~g} \mathrm{~kg}^{-1}$ organic matter, $2.20 \mathrm{~g} \mathrm{~kg} \mathrm{~g}^{-1}$ total N , $1.62 \mathrm{~g} \mathrm{~kg}^{-1}$ total $\mathrm{P}, 28.14 \mathrm{~g} \mathrm{~kg}^{-1}$ total $\mathrm{K}, 182.00 \mathrm{mg} \mathrm{kg}^{-1} \mathrm{NaOH}$ hydrolysable $\mathrm{N}, 112.40 \mathrm{mg} \mathrm{kg}^{-1}$ Olsen $\mathrm{P}$ and $296.60 \mathrm{mg} \mathrm{kg}^{-1}$ $\mathrm{NH}_{4} \mathrm{OAc}$ extractable $\mathrm{K}$ in 2018; and $36.47 \mathrm{~g} \mathrm{~kg}^{-1}, 1.89 \mathrm{~g} \mathrm{~kg}^{-1}, 1.33 \mathrm{~g} \mathrm{~kg}^{-1}, 29.20 \mathrm{~g} \mathrm{~kg}^{-1}, 66.10 \mathrm{mg} \mathrm{kg}^{-1}, 94.50 \mathrm{mg} \mathrm{kg}^{-1}$, and 
$214.30 \mathrm{mg} \mathrm{kg}^{-1}$ in 2019 , respectively. Meanwhile, in Wenjiang the soil contained $28.50 \mathrm{~g} \mathrm{~kg}^{-1}$ organic matter, $1.50 \mathrm{~g} \mathrm{~kg}^{-1}$ total $\mathrm{N}, 0.94 \mathrm{~g} \mathrm{~kg}^{-1}$ total $\mathrm{P}, 17.50 \mathrm{~g} \mathrm{~kg}^{-1}$ total $\mathrm{K}, 137.20 \mathrm{mg} \mathrm{kg}^{-1} \mathrm{NaOH}$ hydrolysable $\mathrm{N}, 50.82 \mathrm{mg} \mathrm{kg}^{-1}$ Olsen $\mathrm{P}$ and 143.10 $\mathrm{mg} \mathrm{kg}{ }^{-1} \mathrm{NH}_{4} \mathrm{OAc}$ extractable $\mathrm{K}$ in 2018; and $29.92 \mathrm{~g} \mathrm{~kg}^{-1}, 1.47 \mathrm{~g} \mathrm{~kg}^{-1}, 1.04 \mathrm{~g} \mathrm{~kg}^{-1}, 16.43 \mathrm{~g} \mathrm{~kg}^{-1}, 72.65 \mathrm{mg} \mathrm{kg}{ }^{-1}, 43.83 \mathrm{mg}$ $\mathrm{kg}^{-1}$, and $164.10 \mathrm{mg} \mathrm{kg}^{-1}$ in 2019 , respectively.

Using two conventional indica rice (Oryza sativa L.) cultivars, 'Huanghuazhan' and 'Guichao II', a two-factor splitplot design experiment with three replicates was conducted in paddy fields at Hanyuan and Wenjiang in 2018 and 2019. At each site, the shading treatment was located in the main plot, and the full sunlight plots constituted the control (CK). After the heading stage, the treatment plants were subjected to shading stress ( $\mathrm{SH}$ ) for $30 \mathrm{~d}$. White cotton fabric with a weave aperture of $0.5 \mathrm{~mm}$ was used to create $2 \mathrm{~m}$ tall screens positioned above the rice. These screens were of sufficient size to maintain good ventilation while reducing radiation by approximately $53 \%$ and preventing lateral sunlight penetration $(\mathrm{Li}$ et al., 2020). There was nonsignificant difference in temperature and humidity between CK and SH plots. In Hanyuan, the shading treatment was conducted from 27 July to 25 August during both years, whereas in Wenjiang, shading was implemented from 30 July to 28 August 2018, and from 2 August to 31 August 2019.

Thirty-day-old healthy seedlings with uniform growth were selected and transplanted by hand at a spacing of $33.3 \times$ $20.0 \mathrm{~cm}$ with two plants per hill. The dimensions of each subplot were $3.0 \times 10.0 \mathrm{~m}$ at Wenjiang in both years, and $4.0 \times 4.0 \mathrm{~m}$ in 2018 and $3.0 \times 8.0 \mathrm{~m}$ in 2019 at Hanyuan. For field fertilization treatment, $180 \mathrm{~kg} \mathrm{~N}^{-1}$ as urea, $90 \mathrm{~kg}$ $\mathrm{P}_{2} \mathrm{O}_{5}$ ha $^{-1}$ as single superphosphate, and $180 \mathrm{~kg} \mathrm{~K}_{2} \mathrm{O}_{\text {ha }}{ }^{-1}$ as potassium chloride were used. The $\mathrm{P}_{2} \mathrm{O}_{5}$ was applied at the start of the experiment and $\mathrm{K}_{2} \mathrm{O}$ was applied in an equal-split at the start of the experiment and at the beginning of the panicle initiation stage. Urea was split-applied as follows: $42 \%$ at transplanting, $18 \%$ at tillering stage, $20 \%$ at panicle initiation, and $20 \%$ at spikelet differentiation stage. Herbicides and pesticides were used to control weeds, insects, and diseases throughout the growth period. Water management measures were implemented according to our previous study (Wang et al., 2015).

The tiller (or panicle) number of rice plants on 60 hills in each plot was counted and three representative hills of the 60 were sampled at three stages: heading, $20 \mathrm{~d}$ after heading (DAH20), and maturity (Zhang et al., 2013). The stem plus sheath (SPS) (for all three stages) and grains (at maturity) were separated from each plant, dried at $105^{\circ} \mathrm{C}$ for $1 \mathrm{~h}$, and oven dried at $75^{\circ} \mathrm{C}$ to constant mass. The dried samples were weighed, and the SPS material was milled and sifted through a $0.5 \mathrm{~mm}$ screen. The stored nonstructural carbohydrates (NSC) content of the SPS material at the three stages was determined by anthrone colorimetry, following Yoshida et al. (1976) with modifications. $0.1 \mathrm{~g}$ dried samples were extracted with $5 \mathrm{~mL} 80 \%$ ethanol in $80{ }^{\circ} \mathrm{C}$ water bath for $30 \mathrm{~min}$, centrifuged $(4000 \mathrm{rpm}$ ) for $10 \mathrm{~min}$, the previous steps were repeated three times, the supernatant was collected and fixed volume to measure the content of soluble sugar with anthrone reagent at $620 \mathrm{~nm}$ wavelength. The rest precipitate was used for starch evaluation; $2 \mathrm{~mL}$ distillate water was added to the precipitate and stored in $80{ }^{\circ} \mathrm{C}$ water bath to evaporate the ethanol. And then the precipitate was gelatinized in the boiling water bath for $15 \mathrm{~min}$. After cool down to room temperature, the sample was extracted with 9.2 and $4.6 \mathrm{~mol} \mathrm{~L}^{-1}$ perchloric acid and centrifuged (4000 rpm) for $10 \mathrm{~min}$, respectively. The supernatant was collected to determine the starch content with anthrone reagent at $620 \mathrm{~nm}$ wavelength. The NSC content was calculated as soluble sugar content plus starch content.

The remobilization of stored NSC from SPS to the grain (RASN), remobilization percentage of removed NSC from SPS to the grain (RPRN), and contribution of RASN to the grain (CRASN) were calculated as described by Yang et al. (2001) and Pan et al. (2011). The specific formulas were as follows:

\section{$\operatorname{RASN}\left(\mathrm{g} \mathrm{m}^{-2}\right)=\mathrm{NSC}$ in SPS at $\mathrm{t} 1-\mathrm{NSC}$ in SPS at $\mathrm{t} 2$}

RPRN $(\%)=($ RASN/NSC in SPS at t1 $) \times 100$;

CRASN $(\%)=($ RASN/Dry kernel mass of grain at maturity $) \times 100$

where, $t$ represents heading, DAH20, or maturity, $\mathrm{t} 1$ and $\mathrm{t} 2$ represents the previous and current stages, respectively.

ANOVA was performed to assess the effect of shading stress in rice stem plus sheath characteristics using the SPSS version 18.0 (IBM, Armonk, New York, USA). Means of treatments were compared between year, site, light treatment and rice variety according to Fisher's protected least significance differences (LSD) test at the 5\% level. Graphs were drawn with GraphPad Prism 5.0 (GraphPad Software, San Diego, California, USA). 


\section{RESULTS}

\section{Effect of shading stress in rice stem plus sheath characteristics}

The effects of year, site, variety, shading stress, and their interaction on SPS dry weight (DWS), grain dry weight (DWG), and SPS NSC characteristics are shown in Table 1. Except for the RPRN, year and site had a significant effect on the DWS, DWG, and SPS NSC characteristics. Both rice variety and light treatment significantly affected stored NSC content, RASN, RPRN, and CRASN. There were nonsignificant interactions between year and light treatment, and among year, site, rice variety, and light treatment and the measured parameters (dry weight and NSC characteristics). However, except for CRASN, the interaction Year $\times$ Site had a marked influence on dry weight and NSC characteristics. Stored NSC content was significantly influenced by the interaction Year $\times$ Variety, whereas DWG was markedly affected by the interaction Site $\times$ Light treatment. Moreover, DWS, stored NSC content, and RPRN were affected by the interaction Site $\times$ Variety. The interaction Variety $\times$ Light treatment had a significant effect on stored NSC content and RPRN. The DWS, RPRN, and CRASN were significantly affected by the interaction Year $\times$ Site $\times$ Light treatment, whereas the interaction Year $\times$ Site $\times$ Variety had a significant effect on stored NSC content, RASN, and CRASN. Furthermore, stored NSC content and RPRN were affected by the interaction Year $\times$ Variety $\times$ Light treatment, and that of Site $\times$ Variety $\times$ Light treatment, respectively.

\section{Stem plus sheath and grain biomass accumulation}

The DWS at the heading stage was markedly higher than that at DAH20, indicating vigorous remobilization of stored DM from these organs between the heading and DAH20 stages (Table 2). The DWS was significantly greater at Hanyuan than at Wenjiang in both years. Nonsignificant difference in DWS was observed at the heading and DAH20 stages at either site between the years. However, shading stress at the Hanyuan site significantly decreased the DWS of 'Guichao II' and 'Huanghuazhan' at the DAH20 stage in 2019 and 'Guichao II' at the DAH20 stage in 2018. Shading stress also markedly decreased the DWS at the maturity stage, leading to a $16.99 \%-22.19 \%$ and $0.93 \%-31.00 \%$ reduction at Wenjiang and Hanyuan, respectively. Furthermore, the average reduction in DWS caused by shading stress was greater for 'Guichao II' than for 'Huanghuazhan' at the DAH20 and maturity stages at both sites. Moreover, the DWG varied between sites and years (Figure 1). Shading stress led to a $6.96 \%-14.29 \%$ and $13.80 \%-22.52 \%$ reduction in DWG at the maturity stage at Wenjiang and Hanyuan, respectively. 'Huanghuazhan' and 'Guichao II' decreased by $11.20 \%-20.92 \%$ and 6.96\%$22.52 \%$ respectively in $2 \mathrm{yr}$ compared with the control. These results suggested that shading stress markedly increased the remobilization of stored DM after the heading stage. However, the effect of shading stress on DWS and DWG differed between rice varieties.

Table 1. Effects of year, site, variety, light treatments, and their interaction on various rice stem plus sheath characteristics.

\begin{tabular}{|c|c|c|c|c|c|c|}
\hline Variation source & DWS & DWG & NSC & RASN & RPRN & CRASN \\
\hline Y (year) & $11.35^{* *}$ & $22.47 * *$ & $680.11 * *$ & $7.02 * *$ & 0.139 & $23.85^{* *}$ \\
\hline $\mathrm{S}$ (site) & $376.92^{* * *}$ & $427.31 * *$ & $645.25^{* *}$ & $57.99 * *$ & 1.32 & $9.47 * *$ \\
\hline V (variety) & 1.34 & 0.426 & $652.92 * *$ & $8.44 * *$ & $24.44 * *$ & $7.73^{* *}$ \\
\hline L (light treatment) & $35.85^{* *}$ & $55.70 * *$ & $1895.64 * *$ & $47.52 * *$ & $328.54 * *$ & $94.21 * *$ \\
\hline $\mathrm{Y} \times \mathrm{S}$ & $41.55^{* *}$ & $22.79 * *$ & $687.51 * *$ & $4.99^{*}$ & $66.06^{* *}$ & 0.209 \\
\hline $\mathrm{Y} \times \mathrm{V}$ & 0.573 & 0.047 & $56.28 * *$ & 0.297 & 0.024 & 2.01 \\
\hline $\mathrm{Y} \times \mathrm{L}$ & 3.48 & 0.159 & 0.002 & 0.041 & 0.708 & 0.183 \\
\hline $\mathrm{S} \times \mathrm{V}$ & $6.43 *$ & 0.024 & $4.98 *$ & 0.007 & $5.99 *$ & 0.316 \\
\hline $\mathrm{S} \times \mathrm{L}$ & 1.81 & $11.28 * *$ & 0.647 & 0.975 & 0.167 & 0.134 \\
\hline $\mathrm{V} \times \mathrm{L}$ & 0.744 & 0.007 & $35.55 * *$ & 2.78 & $8.67 * *$ & 2.32 \\
\hline $\mathrm{Y} \times \mathrm{S} \times \mathrm{V}$ & 2.12 & 0.004 & $171.78 * *$ & $7.95 * *$ & 0.010 & $7.43^{*}$ \\
\hline $\mathrm{Y} \times \mathrm{S} \times \mathrm{L}$ & $8.03 * *$ & 1.35 & 0.436 & 1.73 & $10.12 * *$ & $5.31 *$ \\
\hline $\mathrm{Y} \times \mathrm{V} \times \mathrm{L}$ & 3.87 & 0.020 & $14.39 * *$ & 0.049 & 0.004 & 0.104 \\
\hline $\mathrm{S} \times \mathrm{V} \times \mathrm{L}$ & 1.82 & 0.009 & 2.69 & 0.835 & $9.56 * *$ & 1.57 \\
\hline $\mathrm{Y} \times \mathrm{S} \times \mathrm{V} \times \mathrm{L}$ & 0.105 & 0.275 & 0.518 & 1.99 & 3.98 & 1.41 \\
\hline
\end{tabular}

DWS: Dry weight of stem plus sheath; DWG: dry weight of grain; NSC: stored nonstructural carbohydrate content of stem plus sheath; RASN: remobilization amount of stored NSC; RPRN: redistribution percentage of remobilized NSC; CRASN: contribution of RASN from stem plus sheath to grain.

$*, * *$ Significant at the 0.05 and 0.01 probability levels, respectively. 
Table 2. Dry matter weight of the stem plus sheath (DWS) of rice harvested at heading, $20 \mathrm{~d}$ after heading (DAH20), and maturity stages from plants grown under control (CK) and shade (applied after the heading stage) at Hanyuan and Wenjiang in 2018 and 2019.

\begin{tabular}{|c|c|c|c|c|c|c|c|c|}
\hline \multirow[b]{2}{*}{ Site } & \multirow[b]{2}{*}{ Variety } & \multirow[b]{2}{*}{ Treatment } & \multicolumn{2}{|c|}{ Heading } & \multicolumn{2}{|c|}{ DAH20 } & \multicolumn{2}{|c|}{ Maturity } \\
\hline & & & 2018 & 2019 & 2018 & 2019 & 2018 & 2019 \\
\hline & & & & & $-\mathrm{g} \mathrm{r}$ & & & \\
\hline \multirow[t]{5}{*}{ Wenjiang } & HHZ & CK & $576.00 \mathrm{~b}$ & $600.60 \mathrm{~b}$ & $484.80 \mathrm{bc}$ & $453.60 \mathrm{~d}$ & $494.85 \mathrm{~cd}$ & $405.15 \mathrm{f}$ \\
\hline & & Shading & $617.25 \mathrm{~b}$ & $604.65 b$ & $480.15 b c$ & $422.10 \mathrm{~d}$ & $403.65 \mathrm{e}$ & $336.30 \mathrm{~g}$ \\
\hline & GC & $\mathrm{CK}$ & $638.55 b$ & $643.20 \mathrm{~b}$ & $494.70 b c$ & $439.50 \mathrm{~d}$ & $563.10 \mathrm{abc}$ & $459.00 \mathrm{e}$ \\
\hline & & Shading & $533.85 b$ & $619.20 \mathrm{~b}$ & $430.50 \mathrm{c}$ & $424.35 d$ & $438.15 \mathrm{de}$ & $366.45 \mathrm{fg}$ \\
\hline & & Mean & $591.45 \mathrm{~B}$ & 616.9B5 & $472.50 \mathrm{~B}$ & $434.85 \mathrm{~B}$ & $474.90 \mathrm{~B}$ & $391.80 \mathrm{~B}$ \\
\hline \multirow[t]{5}{*}{ Hanyuan } & $\mathrm{HHZ}$ & $\mathrm{CK}$ & $817.20 \mathrm{a}$ & $922.20 \mathrm{a}$ & $565.20 \mathrm{ab}$ & $773.70 \mathrm{a}$ & $594.75 a$ & $871.50 \mathrm{a}$ \\
\hline & & Shading & $823.65 a$ & $892.65 a$ & $538.65 \mathrm{ab}$ & $613.95 c$ & $589.20 \mathrm{a}$ & $601.35 c$ \\
\hline & GC & $\mathrm{CK}$ & $809.85 a$ & $907.50 \mathrm{a}$ & $603.15 \mathrm{a}$ & $695.55 b$ & $574.20 \mathrm{ab}$ & $695.10 \mathrm{~b}$ \\
\hline & & Shading & $840.00 \mathrm{a}$ & $881.70 \mathrm{a}$ & $502.65 b c$ & $589.65 c$ & $507.00 \mathrm{bcd}$ & $539.55 d$ \\
\hline & & Mean & $822.75 \mathrm{~A}$ & $901.05 \mathrm{~A}$ & $552.45 \mathrm{~A}$ & $668.25 \mathrm{~A}$ & $565.65 \mathrm{~A}$ & $676.95 \mathrm{~A}$ \\
\hline
\end{tabular}

HHZ: 'Huanghuazhan'; GC: 'Guichao II'.

Different uppercase and lowercase letters indicate significant differences between sites and light treatments at the $5 \%$ level, respectively.

Figure 1. Dry matter weight of mature rice grains (DWG) harvested from plants grown under light and shade (applied after the heading stage) at Hanyuan (A) and Wenjiang (B).

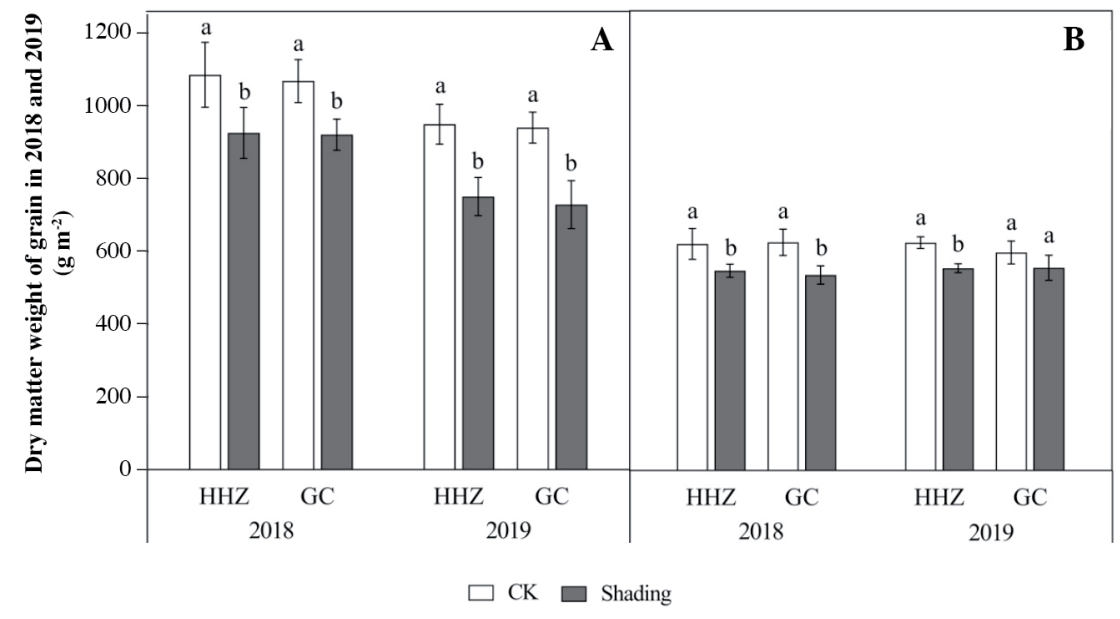

CK: Control; HHZ: ‘Huanghuazhan'; GC: 'Guichao II'.

Different lowercase letters indicate significant differences between light treatments at the $5 \%$ level.

\section{Stored nonstructural carbohydrate content}

Stored NSC contributed approximately one-fifth of the DWS at the heading stage (Table 3). The SPS stored NSC content varied between years and sites. In 2018, the SPS-stored NSC content at the heading and DAH20 stages at Hanyuan was significantly lower than that at Wenjiang, whereas in 2019, the SPS-stored NSC content at the heading stage at both sites, as well as at the DAH20 and maturity stages at Hanyuan were higher. Generally, the SPS-stored NSC content gradually decreased after the heading stage, and shading stress increased the reduction of SPS-stored NSC content, both at the DAH20 and maturity stages, indicating remobilization of NSC from the SPS, especially under shading stress. Shading stress significantly decreased the SPS-stored NSC content after the heading stage, leading to a $23.99 \%-50.30 \%$ and $31.65 \%-61.33 \%$ reduction at the DAH20 and maturity stages at both sites in 2018 and 2019, respectively. However, the effect of shading stress on the SPS-stored NSC content differed between rice varieties. Shading led to a greater decrease in SPS-stored NSC content in 'Guichao II' than in 'Huanghuazhan' at the DAH20 at Wenjiang and Hanyuan, and maturity stages at Hanyuan, respectively, and the decrease in SPS-stored NSC content was greater in 'Huanghuazhan' than in 'Guichao II' at the maturity stage at Wenjiang. 
Table 3. Nonstructural carbohydrate content in the stem plus sheath of rice harvested at heading, $20 \mathrm{~d}$ after heading (DAH20), and maturity stages from plants grown under control (CK) and shade (applied after the heading stage) at Hanyuan and Wenjiang in 2018 and 2019.

\begin{tabular}{|c|c|c|c|c|c|c|c|c|}
\hline \multirow[b]{2}{*}{ Site } & \multirow[b]{2}{*}{ Variety } & \multirow[b]{2}{*}{ Treatment } & \multicolumn{2}{|c|}{ Heading } & \multicolumn{2}{|c|}{ DAH20 } & \multicolumn{2}{|c|}{ Maturity } \\
\hline & & & 2018 & 2019 & 2018 & 2019 & 2018 & 2019 \\
\hline & & & & & $-\mathrm{m}$ & & & \\
\hline \multirow[t]{5}{*}{ Wenjiang } & HHZ & $\mathrm{CK}$ & $208.23 \mathrm{ab}$ & $205.88 \mathrm{c}$ & $218.30 \mathrm{a}$ & $185.17 \mathrm{a}$ & $121.22 \mathrm{a}$ & $104.25 \mathrm{~b}$ \\
\hline & & Shading & $210.59 a$ & $205.18 \mathrm{c}$ & $165.92 \mathrm{~b}$ & $132.90 \mathrm{~d}$ & $52.11 d$ & $54.25 \mathrm{f}$ \\
\hline & GC & $\mathrm{CK}$ & $203.33 b$ & $240.84 a$ & $140.98 \mathrm{c}$ & $150.15 \mathrm{c}$ & $86.71 b$ & $88.84 \mathrm{c}$ \\
\hline & & Shading & $207.59 \mathrm{ab}$ & $245.54 \mathrm{a}$ & $94.55 \mathrm{e}$ & $89.96 \mathrm{f}$ & $55.39 \mathrm{~d}$ & $60.72 \mathrm{e}$ \\
\hline & & Mean & $207.44 \mathrm{~A}$ & $224.36 \mathrm{~A}$ & $154.94 \mathrm{~A}$ & $139.55 \mathrm{~A}$ & $78.86 \mathrm{~A}$ & $77.02 \mathrm{~A}$ \\
\hline \multirow[t]{5}{*}{ Hanyuan } & HHZ & $\mathrm{CK}$ & $194.27 \mathrm{c}$ & $230.96 b$ & $128.42 d$ & $170.62 b$ & $91.99 \mathrm{~b}$ & $122.92 \mathrm{a}$ \\
\hline & & Shading & $192.62 \mathrm{c}$ & $229.07 b$ & $63.83 \mathrm{f}$ & $122.94 \mathrm{e}$ & $43.65 \mathrm{e}$ & $80.22 \mathrm{~d}$ \\
\hline & GC & CK & $202.94 \mathrm{~b}$ & $211.47 \mathrm{c}$ & $72.81 \mathrm{f}$ & $135.74 d$ & $66.98 \mathrm{c}$ & $106.31 \mathrm{~b}$ \\
\hline & & Shading & $205.08 \mathrm{ab}$ & $207.46 \mathrm{c}$ & $40.58 \mathrm{~g}$ & $92.45 \mathrm{f}$ & $25.90 \mathrm{f}$ & $60.52 \mathrm{e}$ \\
\hline & & Mean & 198.73B & $219.74 \mathrm{~A}$ & $76.41 \mathrm{~B}$ & $130.44 \mathrm{~A}$ & $57.13 \mathrm{~A}$ & $92.49 \mathrm{~A}$ \\
\hline
\end{tabular}

HHZ: 'Huanghuazhan'; GC: 'Guichao II'.

Different uppercase and lowercase letters indicate significant differences between sites and light treatments at the $5 \%$ level, respectively.

\section{Remobilization of stored nonstructural carbohydrates}

RASN after the heading stage varied between sites, with 60.00-129.90 and 104.10-159.15 $\mathrm{g} \mathrm{m}^{-2}$ stored NSC remobilized at Wenjiang and Hanyuan, respectively (Table 4). Even though RASN from DAH20 to maturity was markedly lower in 2018, RASN after heading in Hanyuan was significantly improved primarily due to the increase in RASN from heading to DAH20. Nonsignificant difference in RASN from DAH20 to maturity was observed between the control and shading stress treatments. However, increases of $27.99 \%-286.17 \%$ and $25.87 \%-58.60 \%$ in RASN from the heading to the DAH20 stages were recorded under shading stress in Wenjiang and Hanyuan, respectively. Finally, the RASN of Wenjiang and Hanyuan increases by $13.80 \%-89.00 \%$ and $26.16 \%-47.17 \%$ respectively in the mature stage, indicating that shading significantly improved RASN after the heading stage. Furthermore, the increase in RASN of 'Huanghuazhan' (27.81\%$89.00 \%)$ after the heading stage was higher than that of 'Guichao II' (13.80\%-27.48\%) under shading stress, suggesting that the effect of shading stress depended on rice variety.

Table 4. Remobilization of stored nonstructural carbohydrates from the stem plus sheath (RASN) in rice harvested at heading, $20 \mathrm{~d}$ after heading (DAH20), and maturity stages from plants grown under control (CK) and shade (applied after the heading stage) at Hanyuan and Wenjiang in 2018 and 2019.

\begin{tabular}{|c|c|c|c|c|c|c|c|c|}
\hline \multirow[b]{2}{*}{ Site } & \multirow[b]{2}{*}{ Variety } & \multirow[b]{2}{*}{ Treatment } & \multicolumn{2}{|c|}{ Heading-DAH20 } & \multicolumn{2}{|c|}{ DAH20-Maturity } & \multicolumn{2}{|c|}{ Heading-Maturity } \\
\hline & & & 2018 & 2019 & 2018 & 2019 & 2018 & 2019 \\
\hline & & & & & $-\mathrm{g}$ & & & \\
\hline \multirow[t]{5}{*}{ Wenjiang } & $\mathrm{HHZ}$ & CK & $14.10 \mathrm{e}$ & $39.60 \mathrm{e}$ & $45.90 \mathrm{a}$ & $41.85 \mathrm{a}$ & $60.00 \mathrm{e}$ & $81.45 \mathrm{~d}$ \\
\hline & & Shading & $54.45 \mathrm{~d}$ & $68.10 \mathrm{~d}$ & $58.95 \mathrm{a}$ & $37.80 \mathrm{a}$ & $113.40 \mathrm{bcd}$ & $105.90 \mathrm{c}$ \\
\hline & GC & CK & $55.80 \mathrm{~d}$ & $88.95 \mathrm{c}$ & $21.15 \mathrm{~b}$ & $25.20 \mathrm{~b}$ & 76.80de & $114.15 b c$ \\
\hline & & Shading & $75.15 \mathrm{~cd}$ & $113.85 \mathrm{ab}$ & $16.50 \mathrm{~b}$ & $16.05 \mathrm{c}$ & $91.50 \mathrm{cde}$ & $129.90 \mathrm{~b}$ \\
\hline & & Mean & 49.95B & 77.70B & $35.70 \mathrm{~A}$ & $30.30 \mathrm{~A}$ & $85.50 \mathrm{~B}$ & 107.85B \\
\hline \multirow[t]{5}{*}{ Hanyuan } & $\mathrm{HHZ}$ & $\mathrm{CK}$ & $89.40 \mathrm{c}$ & $81.15 \mathrm{~cd}$ & $14.70 \mathrm{~b}$ & $24.60 \mathrm{~b}$ & $104.10 \mathrm{bcd}$ & $105.90 \mathrm{c}$ \\
\hline & & Shading & $124.20 \mathrm{~b}$ & $128.70 \mathrm{a}$ & $8.85 b$ & $27.30 \mathrm{~b}$ & $133.05 \mathrm{ab}$ & $155.85 \mathrm{a}$ \\
\hline & GC & $\mathrm{CK}$ & $120.60 \mathrm{~b}$ & $97.50 \mathrm{bc}$ & $5.55 \mathrm{~b}$ & $20.55 b c$ & $126.15 \mathrm{abc}$ & $117.90 \mathrm{c}$ \\
\hline & & Shading & $151.80 \mathrm{a}$ & $128.40 \mathrm{a}$ & $7.20 \mathrm{~b}$ & $21.90 \mathrm{bc}$ & $159.15 \mathrm{a}$ & $150.30 \mathrm{a}$ \\
\hline & & Mean & $121.50 \mathrm{~A}$ & $108.90 \mathrm{~A}$ & $9.15 \mathrm{~B}$ & $23.55 \mathrm{~A}$ & $130.65 \mathrm{~A}$ & $132.45 \mathrm{~A}$ \\
\hline
\end{tabular}

HHZ: 'Huanghuazhan'; GC: 'Guichao II'.

Different uppercase and lowercase letters indicate significant differences between sites and light treatments at the $5 \%$ level, respectively. 
Remobilization percentage of stored nonstructural carbohydrates

RPRN after heading reached 48.61\%-85.38\% at Wenjiang and 49.62\%-92.36\% at Hanyuan (Table 5). RPRN was lower at Hanyuan than at Wenjiang from DAH20 to maturity stages but higher from heading to DAH20 stages, which, in 2018, resulted in an $11.50 \%$ increase in RPRN after the heading stage. However, RPRN after the heading stage was significantly lower at Hanyuan in 2019, primarily due to the reduction in RPRN from DAH20 to maturity stages. With the exception of the RPRN of 'Guichao II' at Wenjiang in 2019 (from DAH20 to maturity stages), 'Huanghuazhan' at Hanyuan in 2018, and 'Guichao II' at Wenjiang in 2018 (from heading to DAH20 stages), shading stress significantly increased RPRN from heading to DAH20 stages and from DAH20 to maturity stages in both years, leading to a $15.86 \%-73.30 \%$ and $21.29 \%$ $53.55 \%$ increase in RPRN after the heading stage at Wenjiang and Hanyuan, respectively. However, the effectiveness of shading stress on RPRN differed between rice varieties. Shading stress resulted in a greater increase in RPRN of 'Huanghuazhan' than of 'Guichao II' after the heading stage in both years, due to the obvious improvement in RPRN from heading to DAH20 stages at both sites and that from DAH20 to maturity stages at Hanyuan. These results suggest that the increased remobilization of stored NSC from the SPS is a rice plant adaptation to shady conditions.

\section{Contribution of remobilized nonstructural carbohydrates}

The CRASN contributed 9.92\%-23.63\% and 9.63-20.92\% of DWG at Wenjiang and Hanyuan, respectively (Table 6). Nonsignificant differences in CRASN from DAH20 to maturity stages were observed between the control and shading

Table 5. Redistribution percentage of remobilized nonstructural carbohydrates from the stem plus sheath (RPRN) in rice harvested at heading, $20 \mathrm{~d}$ after heading (DAH20), and maturity stages from plants grown under control (CK) and shade (applied after the heading stage) in Hanyuan and Wenjiang in 2018 and 2019.

\begin{tabular}{|c|c|c|c|c|c|c|c|c|}
\hline \multirow[b]{2}{*}{ Site } & \multirow[b]{2}{*}{ Variety } & \multirow[b]{2}{*}{ Treatment } & \multicolumn{2}{|c|}{ Heading-DAH20 } & \multicolumn{2}{|c|}{ DAH20-Maturity } & \multicolumn{2}{|c|}{ Heading-Maturity } \\
\hline & & & 2018 & 2019 & 2018 & 2019 & 2018 & 2019 \\
\hline & & & & & - $\%$ & & & \\
\hline \multirow[t]{5}{*}{ Wenjiang } & $\mathrm{HHZ}$ & $\mathrm{CK}$ & $11.29 \mathrm{f}$ & $32.02 \mathrm{f}$ & $42.47 \mathrm{~b}$ & $49.62 b$ & $48.61 \mathrm{~d}$ & $65.88 \mathrm{~d}$ \\
\hline & & Shading & $40.90 \mathrm{e}$ & $54.72 \mathrm{~cd}$ & $73.15 \mathrm{a}$ & $67.45 \mathrm{a}$ & $84.24 \mathrm{ab}$ & $85.23 \mathrm{a}$ \\
\hline & $\mathrm{GC}$ & $\mathrm{CK}$ & $43.89 \mathrm{e}$ & $57.36 \mathrm{c}$ & $30.12 \mathrm{bcd}$ & $38.08 \mathrm{c}$ & $60.85 c$ & $73.69 \mathrm{c}$ \\
\hline & & Shading & $63.38 \mathrm{c}$ & $74.87 \mathrm{a}$ & $40.49 b$ & $41.03 \mathrm{bc}$ & $78.11 \mathrm{~b}$ & $85.38 \mathrm{a}$ \\
\hline & & Mean & $40.15 \mathrm{~B}$ & $54.74 \mathrm{~A}$ & $46.56 \mathrm{~A}$ & $49.05 \mathrm{~A}$ & $67.95 \mathrm{~A}$ & $77.55 \mathrm{~A}$ \\
\hline \multirow[t]{5}{*}{ Hanyuan } & $\mathrm{HHZ}$ & $\mathrm{CK}$ & $56.37 \mathrm{~d}$ & $37.98 \mathrm{e}$ & $21.13 \mathrm{de}$ & $18.61 \mathrm{~d}$ & $65.57 \mathrm{c}$ & $49.62 \mathrm{f}$ \\
\hline & & Shading & $78.35 \mathrm{~b}$ & $62.78 \mathrm{~b}$ & $23.62 \mathrm{cde}$ & $36.04 \mathrm{c}$ & $83.73 \mathrm{ab}$ & $76.19 \mathrm{c}$ \\
\hline & $\mathrm{GC}$ & $\mathrm{CK}$ & $72.85 \mathrm{~b}$ & $50.80 \mathrm{~d}$ & $12.18 \mathrm{e}$ & $21.73 \mathrm{~d}$ & $76.15 b$ & $61.50 \mathrm{e}$ \\
\hline & & Shading & $88.15 \mathrm{a}$ & $70.23 \mathrm{a}$ & $35.58 \mathrm{bc}$ & $40.03 c$ & $92.36 \mathrm{a}$ & $82.16 \mathrm{~b}$ \\
\hline & & Mean & $79.78 \mathrm{~A}$ & $55.45 \mathrm{~A}$ & $23.13 \mathrm{~B}$ & $29.10 \mathrm{~B}$ & $79.45 \mathrm{~A}$ & $67.37 \mathrm{~B}$ \\
\hline
\end{tabular}

HHZ: 'Huanghuazhan'; GC: 'Guichao II'.

Different uppercase and lowercase letters indicate significant differences between sites and light treatments at the $5 \%$ level, respectively.

Table 6. Contribution of remobilization amount of stored nonstructural carbohydrates to the grain from the stem plus sheath (CRASN) in rice harvested at heading, $20 \mathrm{~d}$ after heading (DAH20), and maturity stages from plants grown under control (CK) and shade (applied after the heading stage) at Hanyuan and Wenjiang in 2018 and 2019.

\begin{tabular}{|c|c|c|c|c|c|c|c|c|}
\hline \multirow[b]{2}{*}{ Site } & \multirow[b]{2}{*}{ Variety } & \multirow[b]{2}{*}{ Treatment } & \multicolumn{2}{|c|}{ Heading-DAH20 } & \multicolumn{2}{|c|}{ DAH20-Maturity } & \multicolumn{2}{|c|}{ Heading-Maturity } \\
\hline & & & 2018 & 2019 & 2018 & 2019 & 2018 & 2019 \\
\hline & & & & & — & & & \\
\hline \multirow[t]{5}{*}{ Wenjiang } & HHZ & $\mathrm{CK}$ & $2.34 \mathrm{~d}$ & $6.41 \mathrm{f}$ & $7.58 \mathrm{~b}$ & $6.73 a$ & $9.92 \mathrm{c}$ & $13.14 \mathrm{c}$ \\
\hline & & Shading & $10.02 \mathrm{c}$ & $12.38 \mathrm{~cd}$ & $10.78 \mathrm{a}$ & $6.89 \mathrm{a}$ & $20.80 \mathrm{a}$ & $19.26 \mathrm{~b}$ \\
\hline & $\mathrm{GC}$ & $\mathrm{CK}$ & $8.97 \mathrm{c}$ & $15.01 \mathrm{bc}$ & $3.40 \mathrm{c}$ & $4.27 \mathrm{~b}$ & $12.36 \mathrm{bc}$ & $19.28 b$ \\
\hline & & Shading & 14.13ab & $20.68 \mathrm{a}$ & $3.10 \mathrm{~cd}$ & $2.95 \mathrm{bcd}$ & $17.23 \mathrm{ab}$ & $23.63 \mathrm{a}$ \\
\hline & & Mean & $8.89 \mathrm{~A}$ & $13.62 \mathrm{~A}$ & $6.22 \mathrm{~A}$ & $5.21 \mathrm{~A}$ & $15.08 \mathrm{~A}$ & $18.83 \mathrm{~A}$ \\
\hline \multirow[t]{5}{*}{ Hanyuan } & HHZ & CK & $8.28 \mathrm{c}$ & $8.53 \mathrm{ef}$ & $1.36 \mathrm{~cd}$ & $2.60 \mathrm{~cd}$ & $9.63 \mathrm{c}$ & $11.13 \mathrm{c}$ \\
\hline & & Shading & $13.44 \mathrm{ab}$ & $17.26 \mathrm{~b}$ & $0.93 \mathrm{~cd}$ & $3.66 \mathrm{bc}$ & $14.37 \mathrm{bc}$ & $20.92 \mathrm{ab}$ \\
\hline & $\mathrm{GC}$ & $\mathrm{CK}$ & $11.18 \mathrm{bc}$ & 10.38de & $0.51 \mathrm{~d}$ & $2.19 \mathrm{~d}$ & $11.69 \mathrm{c}$ & $12.57 \mathrm{c}$ \\
\hline & & Shading & $16.47 \mathrm{a}$ & 17.74ab & $0.79 \mathrm{~cd}$ & $3.02 \mathrm{bcd}$ & $17.26 \mathrm{ab}$ & $20.76 \mathrm{ab}$ \\
\hline & & Mean & $12.34 \mathrm{~A}$ & $13.48 \mathrm{~A}$ & $0.90 \mathrm{~B}$ & $2.87 \mathrm{~B}$ & $13.24 \mathrm{~A}$ & $16.35 \mathrm{~A}$ \\
\hline
\end{tabular}

HHZ: 'Huanghuazhan'; GC: 'Guichao II'.

Different uppercase and lowercase letters indicate significant differences between sites and light treatments at the $5 \%$ level, respectively. 
treatments at both sites and in both years. However, with the exception of 'Guichao II' (Wenjiang) and 'Huanghuazhan' (Hanyuan) in 2018, shading stress significantly increased CRASN from heading to maturity stages, which contributed to 22.56\%-109.68\% and 47.65\%-87.96\% increases in CRASN after heading stage at Wenjiang and Hanyuan, respectively. Shading stress led to a greater increase in CRASN of 'Huanghuazhan' than that of 'Guichao II' after heading stage by increasing CRASN from heading to DAH20 stages. These results suggest that the effect of shading stress on CRASN is primarily dependent on the growth duration from heading to DAH20, and on the rice variety.

\section{DISCUSSION}

Shading stress caused by environmental pollution and extreme weather has become a serious problem in rice production and often results in the reduction of both rice yield and quality (Tie et al., 2016; Chou et al., 2019). A previous study demonstrated the effect of shading stress on photosynthesis in rice (Wang et al., 2015); however, during the reproductive stage, rice yield formation depends not only on the transport of photosynthates from leaves to the reproductive organs but also on the redistribution and transport of carbohydrates stored before heading (Fu et al., 2011). In the present study, the effect of shading on the remobilization of stored NSC from the SPS was examined in detail.

Dry matter accumulation after the heading stage is particularly important for rice yield formation, and it is estimated that approximately $60 \%$ of grain assimilates are produced by photosynthesis during this stage (Wu et al., 2018). Under shading stress (or decreased solar radiation), however, plant photosynthesis is inhibited (Dhruw and Guhey, 2018; Chen et al., 2019), resulting in insufficient photosynthate supply from foliage for grain production. Consequently, rice plants show increased remobilization of stored DM from the SPS to the grain as a compensation mechanism (Ren et al., 2003; Deng et al., 2009). In the present study, shading stress significantly decreased the DWS at the DAH20 and maturity stages, suggesting stronger remobilization of DM from the SPS (Table 2). However, even though more DM was redistributed from the SPS to the grain under shading stress, it was not sufficient to make up for shading damage, leading to a 6.96\%$22.52 \%$ reduction in DWG at the maturity stage (Figure 1). These results are consistent with those of previous studies that have reported a decrease in DM production in rice plants and in the proportion of DM allocated to grain caused by shading stress, which led to insufficient grain filling (Wang et al., 2015; Dhruw and Guhey, 2018).

Crop yield is closely related to the amount of assimilates produced by photosynthesis and depends on the direct accumulation of DM after the heading stage and the remobilization of stored NSC in vegetative organs (especially in the SPS) (Panda and Sarkar, 2014; Deng et al., 2016). In rice, NSC are important photosynthetic products stored in the SPS, which play a significant role in rice grain filling and yield formation (Stella et al., 2016). Generally, redistribution of NSC during the rice grain filling stage can contribute up to 30\% of grain yield (Pan et al., 2011; Panda and Sarkar, 2014). In the present study, the NSC content of the SPS gradually decreased after the heading stage, resulting in $60.00-159.15 \mathrm{~g} \mathrm{~m}^{-2}$ of NSC stored in the SPS being remobilized to the grains, which contributed 9.63\%-23.63\% of the DWG at the maturity stage (Tables 3, 4, and 6).

In addition to genetic factors, environmental conditions also have a significant impact on the remobilization of stored NSC in rice (Zhen et al., 2019). Rice under $\mathrm{CO}_{2}$ enrichment and water stress conditions during the filling period show enhanced remobilization of SPS-stored NSC after the heading stage (Yang et al., 2001; Morita and Nakano, 2011). In the present study, shading stress significantly decreased the SPS-stored NSC content at the DAH20 and maturity stages, leading to a $13.80 \%-89.00 \%$ and $15.86 \%-73.30 \%$ increase in RASN and RPRN, respectively, from heading to maturity stages, which contributed $14.37 \%-23.63 \%$ of the DWG at the maturity stage. These results are consistent with those of Okawa et al. (2003), who demonstrated that rice plants show increased remobilization of stored NSC from the SPS to make up for grain filling limitations caused by the reduction of assimilate sources. Moreover, nonsignificant difference in RASN from DAH20 to maturity stages was observed between the shade-stressed and control plants. Shading stress appeared to enhance the remobilization of stored NSC from the SPS, primarily during the heading to DAH20 period (Table 4), indicating the importance of remobilization of stored NSC during early grain filling stage in rice (Nagata et al., 2001). In general, owing to a greater sink capacity, shading stress led to a greater increase in RASN and RPRN from heading to DAH20. This increase was higher for 'Huanghuazhan' than for 'Guichao II' and higher at Hanyuan than at Wenjiang such that a higher grain yield from 'Huanghuazhan' at Hanyuan was observed. This finding is similar to that of Yoshinaga et al. (2013), who reported that rice NSC remobilization capacity increases with sink capacity. In addition, 
that rice plants at Wenjiang (low light areas), showed higher CRASN and lesser yield loss than that at Hanyuan (high light areas) (Li et al., 2020). Shading led to a $13.13 \%$ and $9.02 \%$ decrease in grain yield at Wenjiang and a $14.20 \%$ and 21.74\% decrease at Hanyuan in 2018 and 2019, respectively. This is consistent with Yang and Zhang (2006), who showed that when photosynthesis decreases, the remobilization ability of NSC from the SPS increases, partially alleviating the yield loss caused by shading. It appears that the grain yield loss caused by shading can be reduced by increasing the remobilization ability of the SPS (especially in low light areas), which might due to the interaction effect between the study sites and the light treatments.

\section{CONCLUSIONS}

In conclusion, we found that the remobilization of stored nonstructural carbohydrates (NSC) from the stem plus sheath (SPS) contributed significantly to rice grain yield. Shading stress after the heading stage significantly increased NSC remobilization from the SPS. The SPS-stored NSC content at the $20 \mathrm{~d}$ after heading (DAH20) and maturity stages decreased significantly, leading to significant increases in the remobilization of NSC from SPS to the grain (RASN), remobilization percentage of redistributed NSC from SPS to the grain and the contribution of RASN to the grain after the heading stage (especially up to DAH20). Furthermore, the effect of shading stress on the NSC characteristics of the SPS varied between the sites and rice varieties. The NSC remobilization ability was higher at Hanyuan than at Wenjiang, and shading stress had a greater influence on NSC remobilization of 'Huanghuazhan' than of 'Guichao II'. It appears that the grain yield loss caused by shading can be reduced by increasing the remobilization ability of the SPS, and it is particularly important for low light areas. Our study indicates that increased accumulation of DM before the heading stage and NSC remobilization from the SPS during the early stages of grain filling are adaptive strategies of rice plants that could reduce yield loss under shading stress.

\section{ACKNOWLEDGEMENTS}

This work was supported by the National Key R\&D Program of China (grant number 2017YFD0300105); the Natural Science Foundation of China (number 31871564), and the Special Project for National Grain Yield and Efficiency Scientific and Technological Innovation of China (grant numbers 2016YFD0300506 and 2017YFD0301700).

\section{REFERENCES}

Bailey-Serres, J., Parker, J.E., Ainsworth, E.A., Oldroyd, G.E., and Schroeder, J.I. 2019. Genetic strategies for improving crop yields. Nature 575(7781):109-118. https://doi.org/10.1038/s41586-019-1679-0.

Chen, H., Li, Q.P., Zeng, Y.L., Deng, F., and Ren, W.J. 2019. Effect of different shading materials on grain yield and quality of rice. Scientific Reports 9(1):9992. https://doi.org/10.1038/s41598-019-46437-9.

Chou, J.M., Xu, Y., Dong, W.J., Xian, T., and Wang, Z. 2019. Research on the variation characteristics of climatic elements from April to September in China's main grain-producing areas. Theoretical and Applied Climatology 137(3-4):3197-3207. https://doi.org/10.1007/s00704-019-02795-y.

Deng, F., Wang, L., Mei, X.F., Li, S.X., Pu, S.L., and Ren, W.J. 2016. Polyaspartate urea and nitrogen management affect nonstructural carbohydrates and yield of rice. Crop Science 56(6):3272-3285. https://doi.org/10.2135/cropsci2016.02.0130.

Deng, F., Wang, L., Yao, X., Wang, J.J., Ren, W.J, and Yang, W.Y. 2009. Effects of different-growing-stage shading on rice grain-filling and yield. Journal of Sichuan Agricultural University 27(03):265-269. https://doi.org/10.3969/j.issn.10002650.2009.03.001. (In Chinese, with English abstract).

Dhruw, A., and Guhey, A. 2018. Effects of low light stress on growth parameters of rice (Oryza sativa L.) genotypes. International Journal of Current Microbiology and Applied Sciences 7(7):472-478. https://doi.org/10.20546/ijcmas.2018.707.057.

Fu, J., Huang, Z.H., Wang, Z.Q., Yang, J.C., and Zhang, J.H. 2011. Pre-anthesis non-structural carbohydrate reserve in the stem enhances the sink strength of inferior spikelets during grain filling of rice. Field Crops Research 123(2):170-182. https://doi. org/10.1016/j.fcr.2011.05.015.

Fukagawa, N.K., and Ziska, L.H. 2019. Rice: Importance for global nutrition. Journal of Nutritional Science and Vitaminology 65:S2-S3. https://doi.org/10.3177/jnsv.65.s2.

Ibarrola-Rivas, M.J., Granados-Ramírez, R., and Nonhebel, S. 2017. Is the available cropland and water enough for food demand? A global perspective of the Land-Water-Food nexus. Advances in Water Resources 110:476-483. https://doi. org/10.1016/j.advwatres.2017.09.018. 
Li, Q.P., Deng, F., Chen, H., Zeng, Y.L., Li, B., Zhong, X.Y., et al. 2020. Shading decreases rice yield by impeding grain filling progress after heading. Agronomy Journal 112(5):4018-4030. https://doi.org/10.1002/agj2.20372.

Liang, W.X., Zhang, Z.C., Wen, X.X., Liao, Y.C., and Liu, Y. 2017. Effect of non-structural carbohydrate accumulation in the stem pre-anthesis on grain filling of wheat inferior grain. Field Crops Research 211:66-76. https://doi.org/10.1016/j.fcr.2017.06.016.

Liu, K., Yang, R., Lu, J., Wang, X.Y., Lu, B.L., Tian, X.H., et al. 2019. Radiation use efficiency and source-sink changes of super hybrid rice under shade stress during grain-filling stage. Agronomy Journal 111(4):1788-1798. https://doi.org/10.2134/ agronj2018.10.0662.

Morita, S., and Nakano, H. 2011. Nonstructural carbohydrate content in the stem at full heading contributes to high performance of ripening in heat-tolerant rice cultivar Nikomaru. Crop Science 51(2):818-828. https://doi.org/10.2135/cropsci2010.06.0373.

Nagata, K., Yoshinaga, S., Takanashi, J., and Terao, T. 2001. Effects of dry matter production, translocation of nonstructural carbohydrates and nitrogen application on grain filling in rice cultivar Takanari, a cultivar bearing a large number of spikelets. Plant Production Science 4(3):173-183. https://doi.org/10.1626/pps.4.173.

Okawa, S., Makino, A., and Mae, T. 2003. Effect of irradiance on the partitioning of assimilated carbon during the early phase of grain filling in rice. Annals of Botany 92(3):357-364. https://doi.org/10.1093/aob/mcg147.

Pan, J.F., Cui, K.H., Wei, D., Huang, J.L., Xiang, J., and Nie, L.X. 2011. Relationships of non-structural carbohydrates accumulation and translocation with yield formation in rice recombinant inbred lines under two nitrogen levels. Physiologia Plantarum 141(4):321-331. https://doi.org/10.1111/j.1399-3054.2010.01441.x.

Panda, D., and Sarkar, R.K. 2014. Mechanism associated with nonstructural carbohydrate accumulation in submergence tolerant rice (Oryza sativa L.) cultivars. Journal of Plant Interactions 9(1):62-68. https://doi.org/10.1080/17429145.2012.763000.

Priyanka, G., Lal, B., Nayak, A.K., Raja, R., Panda, B.B., Tripathi, R., et al. 2019. Inter-relationship between intercepted radiation and rice yield influenced by transplanting time, method, and variety. International Journal of Biometeorology 63(3):337-349. https://doi.org/10.1007/s00484-018-01667-w.

Ray, D.K., West, P.C., Clark, M., Gerber, J.S., Prishchepov, A.V., and Chatterjee, S. 2019. Climate change has likely already affected global food production. PLOS ONE 14(5):e217148. https://doi.org/10.1371/journal.pone.0217148.

Ren,W.J., Yang, W.Y., Fan, G.Q., Zhu, X.M., Ma,Z.H., and Xu, J.W.2003. Effect of low light on dry matter accumulation and yield of rice. Journal of Sichuan Agricultural University 21(4):292-296. https://doi.org/10.3321/j.issn:0496-3490.2003.05.027. (In Chinese, with English abstract).

Shao, L.P., Li, G., Zhao, Q.N., Li, Y.B., Sun, Y.T., Wang, W.N., et al. 2019. The fertilization effect of global dimming on crop yields is not attributed to an improved light interception. Global Change Biology 26:1697-1713. https://doi.org/10.1111/gcb.14822.

Slewinski, T.L. 2012. Non-structural carbohydrate partitioning in grass stems: a target to increase yield stability, stress tolerance, and biofuel production. Journal of Experimental Botany 63:4647-4670. https://doi.org/10.1093/jxb/ers124.

Stella, T., Bregaglio, S., and Confalonieri, R. 2016. A model to simulate the dynamics of carbohydrate remobilization during rice grain filling. Ecological Modelling 320:366-371. https://doi.org/10.1016/j.ecolmodel.2015.10.026.

Tie, X.X., Huang, R.J., Dai, W.T., Cao, J.J., Long, X., Su, X.L., et al. 2016. Effect of heavy haze and aerosol pollution on rice and wheat productions in China. Scientific Reports 6(1):1-6. https://doi.org/10.1038/srep29612.

Wang, L., Deng, F., and Ren, W.J. 2015. Shading tolerance in rice is related to better light harvesting and use efficiency and grain filling rate during grain filling period. Field Crops Research 180:54-62. https://doi.org/10.1016/j.fcr.2015.05.010.

Wei, H.Y., Zhu, Y., Qiu, S., Han, C., Hu, L., Xu, D., et al. 2018. Combined effect of shading time and nitrogen level on grain filling and grain quality in japonica super rice. Journal of Integrative Agriculture 17(11):2405-2417. https://doi.org/10.1016/ S2095-3119(18)62025-8.

Wu, W., Nie, L.X., Liao, Y.C., Shah, F., Cui, K.H., Wang, Q., et al. 2013. Toward yield improvement of early-season rice: Other options under double rice-cropping system in central China. European Journal of Agronomy 45:75-86. https://doi. org/10.1016/j.eja.2012.10.009.

Wu,H.,Xiang,J.,Zhang,Y.P.,Zhang, Y.K.,Peng,S.B.,Chen,H.Z., et al.2018.Effects of post-anthesis nitrogen uptake and translocation on photosynthetic production and rice yield. Scientific Reports 8(1):1-11. https://doi.org/10.1038/s41598-018-31267-y.

Yang, J.C., and Zhang, J.H. 2006. Grain filling of cereals under soil drying. New Phytologist 169(2):223-236. https://doi. org/10.1111/j.1469-8137.2005.01597.x.

Yang, J.C., Zhang, J.H., Wang, Z.Q., Zhu, Q.S., and Wang, W. 2001. Remobilization of carbon reserves in response to water deficit during grain filling of rice. Field Crops Research 71(1):47-55. https://doi.org/10.1016/S0378-4290(01)00147-2.

Yoshida, S., Forno, D., Cock, J., and Gomez, K. 1976. Determination of sugar and starch in plant tissue. p. 46-49. In Yoshida, S. (ed.) Laboratory manual for physiological studies of rice. International Rice Research Institute, Los Baños, Philippines.

Yoshinaga, S., Takai, T., Arai-Sanoh, Y., Ishimaru, T., and Kondo, M. 2013. Varietal differences in sink production and grainfilling ability in recently developed high-yielding rice (Oryza sativa L.) varieties in Japan. Field Crops Research 150:74-82 . https://doi.org/10.1016/j.fcr.2013.06.004.

Zhang, Z.J., Chu, G., Liu, L.J., Wang, Z.Q., Wang, X.M., Zhang, H., et al. 2013. Mid-season nitrogen application strategies for rice varieties differing in panicle size. Field Crops Research 150:9-18. https://doi.org/10.1016/j.fcr.2013.06.002.

Zhen, F.X., Zhou, J.J., Mahmood, A., Wang, W., Chang, X.N., Liu, B., et al. 2019. Quantifying the effects of short-term heat stress at booting stage on nonstructural carbohydrates remobilization in rice. The Crop Journal 8(2):194-212. https://doi. org/10.1016/j.cj.2019.07.002. 